\title{
Article \\ Supervision of the Default Risk of Online Car-Hailing Platform from an Evolutionary Game Perspective
}

\author{
Zhicheng Weng * and Pinliang Luo
}

check for updates

Citation: Weng, Z.; Luo, P.

Supervision of the Default Risk of Online Car-Hailing Platform from an Evolutionary Game Perspective. Sustainability 2021, 13, 555. https:// doi.org/10.3390/su13020555

Received: 27 November 2020 Accepted: 5 January 2021 Published: 8 January 2021

Publisher's Note: MDPI stays neutral with regard to jurisdictional clai$\mathrm{ms}$ in published maps and institutional affiliations.

Copyright: (C) 2021 by the authors. Licensee MDPI, Basel, Switzerland. This article is an open access article distributed under the terms and conditions of the Creative Commons Attribution (CC BY) license (https:// creativecommons.org/licenses/by/ $4.0 /)$.
School of Management, Fudan University, Shanghai 200433, China; plluo@fudan.edu.cn

* Correspondence: zcweng16@fudan.edu.cn; Tel.: +86-021-3312-8732

\begin{abstract}
Online car-hailing services are becoming a key component of the public transportation system, despite there being some certain risks, especially default risk. Turning to the evolutionary game method, this research constructed an evolutionary game model of online car-hailing platform, and then analyzed the equilibrium state of three scenarios (i.e., no supervision, internal supervision of platform enterprises, and external supervision of regulators), followed by carrying out a simulation. The results showed that to realize the evolution stability strategies (ESS) of default risk control, a strong credit constraint or the establishment of a coordinated supervision mode with appropriate intensity are needed. On this basis, this research puts forward the coordinated "platform enterprise + regulator" supervision mode, as well as the following four specific strategies: Promoting the construction of a credit system, strengthening the construction of laws and regulations, establishing a service process control mechanism, and introducing innovative regulatory means.
\end{abstract}

Keywords: online car-hailing platform; default risk; coordinated supervision mode; evolutionary game; simulation

\section{Introduction}

Information and communications technology (ICT) plays an increasingly important role in the growth in many kinds of industrial fields [1-4]. Czernich et al. [2], Han and Zhu [3] conducted empirical study to measure the impact of broadband infrastructure on economic growth, while Guo and Luo [4] studied the relationship between Internet and total factor productivity (TFP), and all of them came to the same conclusion that ICT is critical to the economic growth. Due to the widespread use of ICT, many industries have undergone tremendous changes, thus giving birth to the sharing economy [5]. One of the typical applications of the sharing economy in the area of transportation is online car-hailing services [6], which alleviate the pressure of taking a taxi, especially in rush hour. The twosided platform mode [7,8] is the most common operating mode in the online car-hailing industry; hence, we also refer to online car-hailing platform as a general term composed of the stakeholders and the transaction relationships of online car-hailing services.

The stakeholders in online car-hailing platform include the online car-hailing service operating enterprises (hereinafter referred to as platform enterprises), drivers, and passengers. In the two-sided market theory, drivers and passengers are referred to as platform users, that is, the payoff of either group of users gained from the transaction depend on the number of other groups of users [8]. Specifically, platform enterprises simultaneously bridge between drivers and passengers, and drivers are the platform users who provide point-to-point transportation services, while passengers are the platform users who need this service. On the one hand, drivers' income depends on the number of passengers, as the more passengers, the greater the potential for drivers to provide their services, which increases their income. On the other hand, the utility of passengers depends on the number of drivers, as the more drivers, the shorter the waiting time for their services [1]. Additionally, this characteristic of two-sided platform promotes the rapid development 
of the online car-hailing market. By June 2020, the users of online car-hailing services in China had reached 340 million, covering $36.2 \%$ of the Internet users in China [9].

Due to their ability to reduce the uncertainty and anxiety of waiting for a traffic tool $[10,11]$, online car-hailing services are becoming a key component of the public transportation system [12]. Though the online car-hailing market has achieved vigorous development, there still exist some certain risks [13], especially default risk. On the one hand, the operating mode of the online car-hailing services exacerbates the information asymmetry in the market. Due to the two-sided platform characteristic, the relationship between drivers and passengers is formed after the establishment of the agent relationship between the platform enterprises and the platform users [14]. As a result, the information asymmetry problem exists not only between drivers and passengers, but also between the platform enterprises and platform users [15]. On the other hand, the application of ICT largely reduces the default cost of platform users. Due to the openness of the transaction environment, the trust mechanism between drivers and passengers has changed, which not only leads to information distortion with high credit [16], but also weakens the credit constraint on platform users' default behavior. Specifically, the default risk of drivers is reflected in situations such as deviations from the prescribed route. In other words, the default behaviors of drivers refer to providing the abnormal service instead of the correct point-to-point transportation services. According to the information released by the WeChat platform of the Information Office of Shanghai Government, the complaints about online car-hailing services accepted by the Shanghai Transportation Commission focus on four aspects (see Table 1). As can be seen from Table 1, the total number of complaints for online car-hailing service of the first quarter and second quarter of 2020 are much less than those of 2019, for that the use of public transportation has dropped sharply in the early 2020 due to the outbreak of corona virus disease 2019 (COVID-19). However, as the number of complaints for "higher charge" and "bad service quality" are still relatively large, the default problem has not been alleviated. As for passengers, the typical manifestation of default risk is the refusal to pay their fare.

Table 1. Main complaints for online car-hailing services.

\begin{tabular}{ccccccccc}
\hline Complaint & 2018 Q4 & 2019 Q1 & 2019 Q2 & 2019 Q3 & 2019 Q4 & 2020 Q1 & 2020 Q2 & 2020 Q3 \\
\hline Bad service quality & 171 & 182 & 126 & 386 & - & 71 & 110 & 383 \\
Higher charge & 275 & 399 & 650 & 942 & - & 502 & 787 & 903 \\
Unfinished order & 288 & 266 & 320 & 177 & - & 64 & 56 & 400 \\
Incorrect vehicle & 170 & 152 & 162 & 80 & - & 21 & 70 & 228 \\
information & & & & & & \\
\hline
\end{tabular}

Note: The data of the fourth quarter of 2019 were not disclosed. The data were obtained from the WeChat platform of the Information Office of Shanghai Government (https://mp.weixin.qq.com/mp/profile_ext?action=home\&_biz=MjM5NTA5NzYyMA==).

Although there have been plenty of studies on the online car-hailing market, most of them focus on the market prospect [17-19], business mode [20,21], and influence [11,22-24]. Specifically, for the market prospect, Katzev [17] investigated the motivation to participate in car sharing, while Shaheen and Martin [18] assessed the market potential. Firnkorn and Müller [19] described the free-floating carsharing-systems and reports the potential of private car reduction. As the market grows more mature, more scholars like Vanoutrive et al. [20] and Yang and Tu [21] focused on the internal operating mechanism such as transaction mechanism, value creation mechanism. As for the influence, Rogers [11] described the social cost of the online car-hailing service in detail, and Chapman et al. [22] paid attention to the relationship between car-sharing and car-use, while Jung and Koo [23] studied the impact on greenhouse gas emission. Rayle et al. [24] studied how online car-hailing service impacted the use of public transit and overall vehicle travel. In addition, some scholars like Anderson [25] and Glöss et al. [26] compared the pattern of online car-hailing services and traditional taxi services. However, research on default risk is scarcer, especially in terms of theoretical and empirical research. Fortunately, default risk is not a concept unique to the online car-hailing market, and the conclusions obtained 
from other market studies also have certain applicability. As for default risk management measures, there is an abundance of research results, which can be divided into two major categories, namely administrative management and market management. Administrative management includes improving laws and regulations [27], establishing a service responsibility system [28], and promoting the construction of a credit information system [29], while market management includes the introduction of third parties [30-33] and applying new monitor technology [34]. For example, Lizzeri [30] and Albano and Lizzeri [31] studied how third parties like certification intermediaries reduced the information asymmetry, so as the default risk. Stiglitz and Weiss [32] and Bester [33] focused on the credit markets, and investigated the role of third parties under imperfect information environment. As for the default risk supervision mode, the existing theoretical research mainly focuses on a single regulation subject or regulation object. For example, Gu et al. [35] studied the supervision mode that regulators monitor the platform enterprises and analyzed its influence on the default risk of the Peer-to-Peer (P2P) lending market. Wang et al. [36] compared three modes, including private supervision, public supervision, and coordinated supervision, from the perspective of dynamic game, focusing on the supervision on sellers. However, the supervision of the default risk pertaining to online car-hailing platform is a complex problem related to two regulation subjects and two regulation objects, and it is of great practical significance to discuss how to supervise and control this default risk.

This research intended to apply the evolutionary game theory to analyze the supervision of the default risk of online car-hailing platform, for the evolutionary game theory combines game theory with dynamic evolution process analysis [37] and has been widely used to study the sharing economy [38] and default risk control [39]. This research focused on answering the following questions: (1) Can default risk be controlled under a no supervision environment? (2) From the perspective of pursuing own interests, can platform enterprises realize the control of default risk under its own interest constraint? (3) How should the regulators supervise platform enterprises in order to achieve the goal of controlling the default risk of platform users?

The remainder of this paper is organized as follows: Section 2 constructs the evolutionary game model and analyzes the ESS of each scenario. Section 3 shows the numerical stimulation and proposes the supervision mode and strategies. Finally, conclusions are drawn in Section 4.

\section{Materials and Methods}

\subsection{Model Framework and Assumption}

\subsubsection{Model Framework}

Smith and Price put forward the concept of ESS [40], which laid the foundation of evolutionary game theory. Since then, the application of evolutionary game theory has gradually infiltrated many sectors, like sociology, economics, and other fields. In reality, the game between the stakeholders in online car-hailing platform repeated many times; hence, it is appropriate and reasonable to analyze the problem of default risk from an evolutionary game perspective. Furthermore, the dynamic evolutionary mechanism should be used to find the ESS in each evolutionary game model, and the evolutionary mechanism based on differential equations [41-43] is most commonly used [44].

The overall framework of the default risk control mechanism studied in our research is shown in Figure 1. First, an evolutionary game model of the platform without supervision was studied, to analyze how the credit constraint can realize the control of default risk. Second, considering the supervision function of the platform enterprises, this research investigated whether platform enterprises can realize the control of default risk under its own interest constraint. Third, external supervision was introduced to control the default risk of platform users, so as to discuss the different ways of external supervision. 


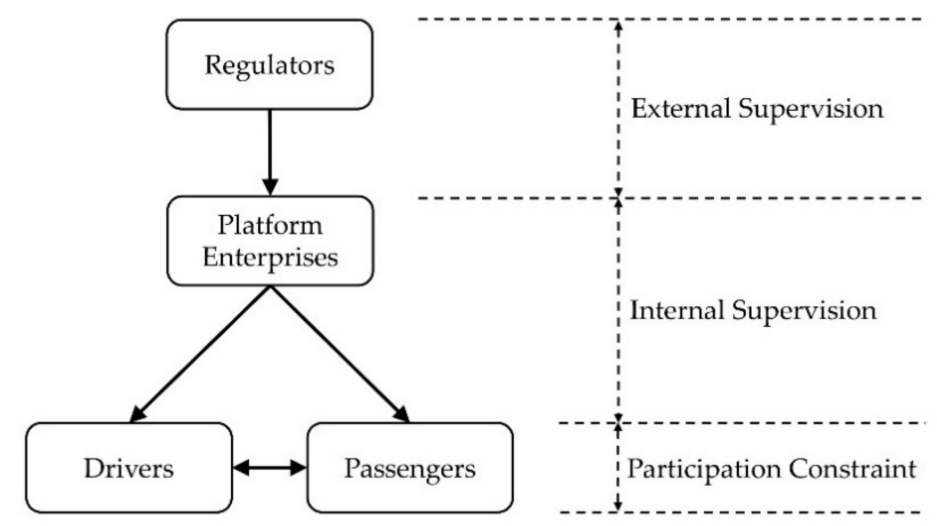

Figure 1. The overall framework of the default risk control mechanism of online car-hailing platform.

\subsubsection{Model Assumption}

As this evolutionary game model aims to analyze the default risk of platform users, we focused on the strategies about default behavior and supervision. This research assumes that all stakeholders are finite rational people, and due to the information asymmetry, their decisions are likely to affect the decisions of other game participants. From the perspective of the drivers, they can choose to provide the right point-to-point transportation services (hereinafter referred to as "Normal Service", S1), which means the driving route is safe and correct. Additionally, the drivers can take detours or other abnormal actions (hereinafter referred to as "Abnormal Service", S2) to seek more profits, both physically and mentally. As for the passengers, they may pay for the services after arriving at the destination (hereinafter referred to as "No Default", B1) or may not (hereinafter referred to as "Default", B2). As for the platform enterprises, it is possible for them to make an effort to identify and punish the default behavior of platform users (hereinafter referred to as "Supervision", T1). Taking the cost and difficulty of supervision into consideration, it is also reasonable for the platform enterprises to choose not to monitor the default behavior (hereinafter referred to as "No Supervision", T2). Each game participant has two strategies that add up to eight sets of strategy combinations, and the extended type of the game between them is depicted in Figure 2.

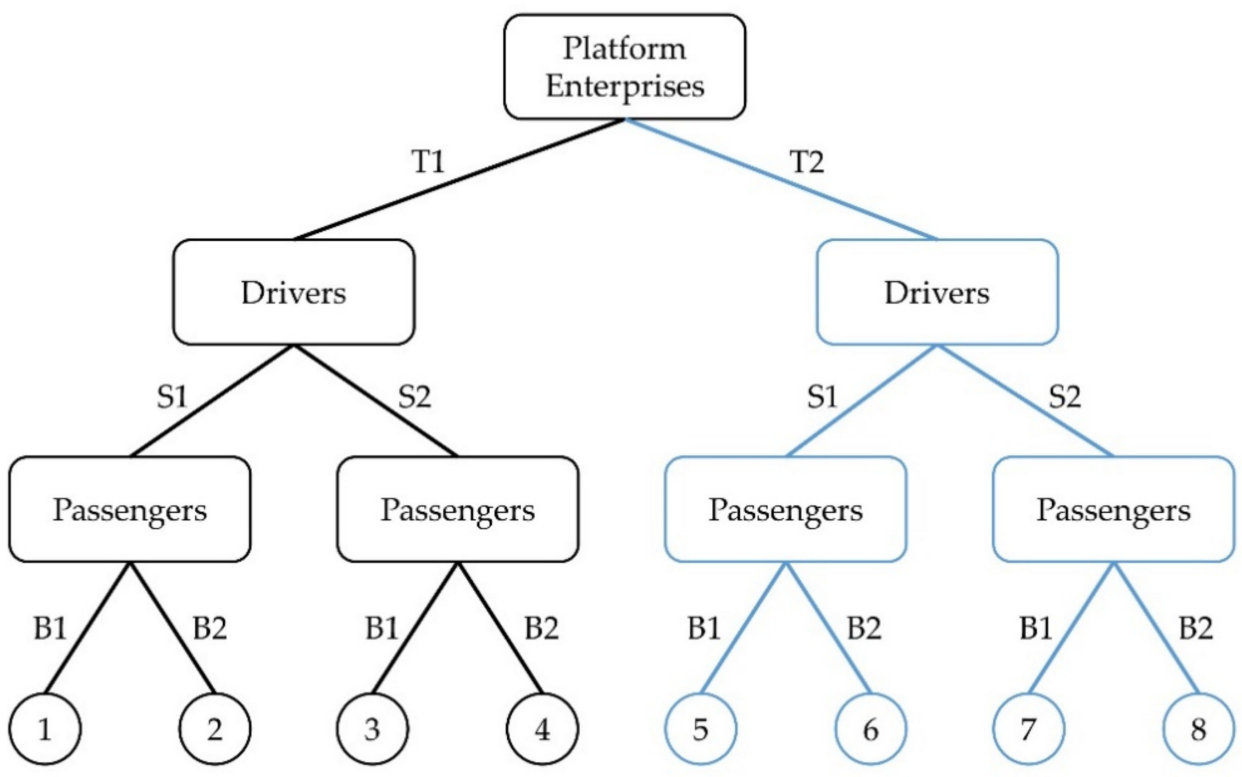

Figure 2. The extended type of the game between platform enterprises, drivers, and passengers. 
Let $x$ be the possibility of the drivers providing a right point-to-point transportation service; then, $1-x$ represents the possibility of the drivers providing an abnormal service; $x$ satisfies the condition of $0 \leq x \leq 1$. Similarly, $y$ represents the possibility of the passengers obeying the rule, while $1-y$ represents the possibility of the passengers taking default action; $y$ satisfies the condition of $0 \leq y \leq 1$. $z$ represents the possibility of the platform enterprises monitoring the behavior of platform users, and $1-z$ represents the possibility of the platform enterprises not monitoring the behavior of platform users; $z$ satisfies the condition of $0 \leq z \leq 1$.

This research investigated three scenarios. First of all, we considered the scenario that the platform enterprise only matches drivers with passengers for transactions in order to analyze the necessity of supervision of said platform enterprise to control the default risk of platform users. We refer to the evolutionary game model under this scenario as the basic model. Suppose that the price of the online car-hailing service is $R$ and the commission charged by the platform enterprise is $K$. The utility that the passenger can get after using the online car-hailing service is $U$. Naturally, it can be assumed that $U>R$, otherwise passengers would not use the online car-hailing service. When drivers provide an abnormal service, they can gain additional revenues $M$, and passengers' utility slides down to $U^{\prime}$. Naturally, we assume a $U-U^{\prime}>M$, which means that the loss that the passenger suffers as a result of the driver providing an abnormal service exceeds the driver's additional gains (otherwise the abnormal online car-hailing service would indeed improve social welfare). When the passenger chooses the "Default" strategy, they do not pay the service fare.

Similar to the practice of Gu et al. [35], we assumed that there is a credit mechanism and risk transition effect on online car-hailing platform, that is, when the drivers conduct the default behaviors, they are added to the platform's blacklist or are blocked from other credit mechanisms, which leads to credit loss $L_{S}$, and the platform enterprises shall bear the credit loss $L_{S T}$ due to the damage to their reputation in the meantime. Similarly, in the case of the passengers conducting the default behaviors, they are also added to the platform's blacklist or are blocked from other credit mechanisms, which leads to credit loss $L_{B}$, and the platform enterprises are required to bear the credit loss $L_{B T}$ since their reputation is damaged.

On the basis of the basic model, this research further considered the supervision of the platform enterprises, referred to as scenario 2, in order to verify the effectiveness of internal supervision and the necessity of external supervision. It is assumed that the supervision cost of the platform enterprise is $C$, and that the platform enterprises punish the defaulted drivers with $W_{S}$ and the defaulted passengers with $W_{B}$. We also assumed that there would be no reputation loss for platform enterprises if the defaulted users are penalized. Furthermore, this research considered the external supervision of the regulators to analyze the effectiveness and patterns of external supervision, referred to as scenario 3 . We assumed that the post-event penalty imposed by the regulator on platform enterprises is $W$, while the in-event penalty is $W^{\prime}$. Actually, it is the dual problem that to punish the default behavior or to reward the compliance behavior, and we focused on the punishment in our research. Actually, we could adjust the parameters to reflect different market environment (i.e., the deduction of $U$ and $U^{\prime}$ can reflect the fear of being infected in the time of COVID-19 pandemic, and the deduction of $K$ can reflect the subsidies). However, this research mainly focused on the supervision mode; hence, we would not discuss the impact of the sudden events furtherly. The meanings of the related parameters are shown in Table 2. 
Table 2. Definition of the parameters related to different game strategies.

\begin{tabular}{cl}
\hline Parameter & \multicolumn{1}{c}{ Definition } \\
\hline$x$ & The possibility of the drivers taking the "Normal Service" strategy \\
$y$ & The possibility of the passengers taking the "No Default" strategy \\
$z$ & The possibility of the platform enterprises taking the "Supervision" strategy \\
$R$ & The price of the online car-hailing service \\
$K$ & The commission charged by the platform enterprises \\
$U$ & The utility that the passengers get from a normal service \\
$U^{\prime}$ & The utility that the passengers get from an abnormal service \\
$M$ & The additional revenue that the drivers get from an abnormal service \\
$L_{S}$ & The credit loss that the drivers bear when they default \\
$L_{S T}$ & The credit loss that the platform enterprises bear when the drivers default \\
$L_{B}$ & The credit loss that the passengers bear when they default \\
$L_{B T}$ & The credit loss that the platform enterprises bear when the passengers default \\
$C$ & The supervision cost of the platform enterprises \\
$W_{S}$ & The punishment imposed by the platform enterprises on the defaulted drivers \\
$W_{B}$ & The punishment imposed by the platform enterprises on the defaulted passengers \\
$W$ & The post-event penalty imposed by the regulators on the platform enterprises \\
$W^{\prime}$ & The in-event penalty imposed by the regulators on the platform enterprises \\
\hline
\end{tabular}

\subsection{Equilibrium Analysis of the Evolutionary Game}

Based on the abovementioned model assumptions, this research conducted equilibrium analysis of the evolutionary game of three different scenarios, and the block diagram of the analysis is shown in Figure 3.

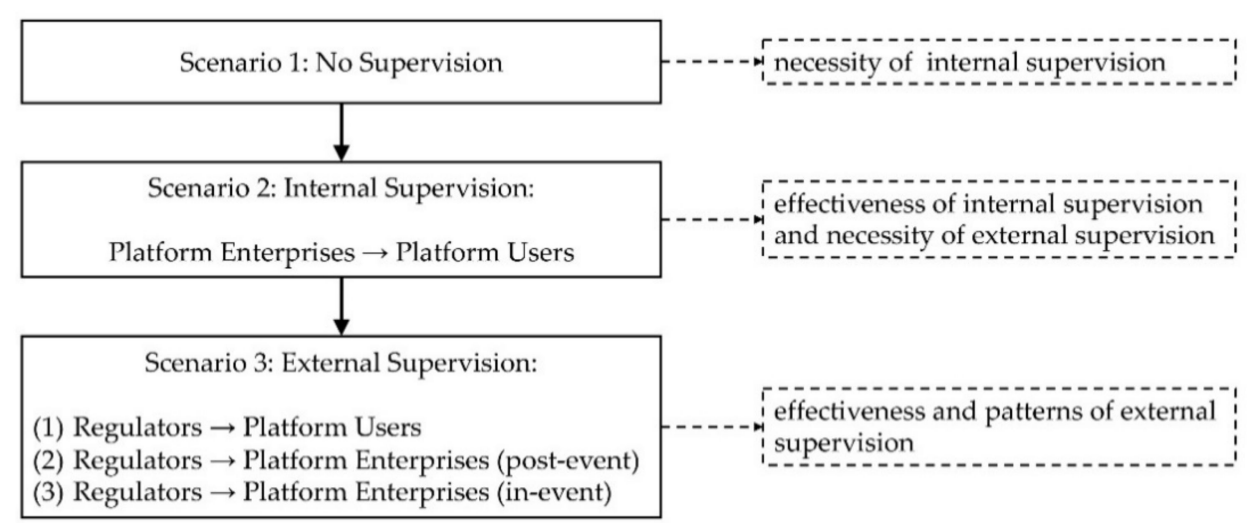

Figure 3. The block diagram of evolutionary game analysis.

\subsubsection{Scenario 1: No Supervision}

In scenario 1, we concentrated on the behavior of two platform users, and assumed that the platform enterprises only match drivers with passengers for transactions. In other words, we can assume that the platform enterprises adopt the "No Supervision" strategy (the extended type of this game is depicted as the part painted blue in Figure 2). When the driver chooses the "Normal Service" strategy and the passenger chooses the "No Default" strategy, the decision choice of the two parties is (S1, B1). Thus, the driver can gain a revenue deducted from commission $R-K$, the passenger can gain $U-R$, while the platform enterprise can gain the commission fee K. Actually, we do not take the cost of providing the service into consideration, because this cost is accounted for in all strategy combinations and the difference of cost between providing a normal or abnormal service can be reflected in the additional revenues $M$. When the driver chooses the "Normal Service" strategy and the passenger chooses the "Default" strategy, the decision choice of the two parties is (S1, B2). Thus, the driver cannot achieve their desired service price and their payoff is 0 . The passenger obtains a utility $U$ but suffers a loss $L_{B}$. Moreover, the platform enterprise cannot secure a commission fee and suffer a loss $L_{B T}$. When the driver 
chooses the "Abnormal Service" strategy and the passenger chooses the "No Default" strategy, the decision choice of the two parties is (S2, B1). Thus, the driver achieves their desired service price and an additional revenue, and their payoff is $M+R-K-L_{S}$. The passenger obtains a utility $U^{\prime}$ and pay $R$, and the platform enterprise can secure a commission fee $K$ but suffer a loss $L_{S T}$. When the driver chooses the "Abnormal Service" strategy and the passenger chooses the "Default" strategy, the decision choice of the two parties is (S2, B2). Thus, the driver's payoff is $M-L_{S}$ and the passenger obtains a utility $U^{\prime}$, while the platform enterprises suffer a loss $L_{S T}+L_{B T}$. In this way, we can determine the profit of every strategy combination, as shown in Table 3.

Table 3. Benefit matrix of the online car-hailing platform of scenario 1.

\begin{tabular}{ccc}
\hline & No Default & Default \\
\hline Normal Service & $R-K, U-R, K$ & $0, U-L_{B},-L_{B T}$ \\
Abnormal Service & $M+R-K-L_{S}, U^{\prime}-R, K-L_{S T}$ & $M-L_{S}, U^{\prime}-L_{B},-L_{S T}-L_{B T}$ \\
\hline
\end{tabular}

Note: The first item is the payoff of the drivers, the second item is the payoff of the passengers, and the third item is the payoff of the platform enterprises.

The payoff of different strategy combinations is listed in Table 3. According to the evolutionary game theory, when the return of a certain strategy is higher than the average return of the whole game system, this strategy will gradually evolve and develop in the system $[45,46]$, and we can use the replicated dynamic equation to describe this evolving process $[47,48]$.

The expected payoff of the drivers taking the "Normal Service" strategy can be expressed as:

$$
E_{S 1}=y(R-K)
$$

The expected payoff of the drivers taking the "Abnormal Service" strategy can be expressed as:

$$
E_{S 2}=M-L_{S}+y(R-K) .
$$

Given that the probability of the drivers taking the "Normal Service" strategy and the "Abnormal Service" strategy is $x$ and $(1-x)$, respectively, the expected payoff of the drivers can be expressed as:

$$
\bar{E}_{S}=x E_{S 1}+(1-x) E_{S 2} .
$$

The evolution of time is denoted as $t$, and the replicated dynamic equation of $E_{S 1}$ is given by:

$$
F_{1}(x)=\frac{d x}{d t}=x\left(E_{S 1}-\bar{E}_{S}\right)=x(1-x)\left(L_{S}-M\right)
$$

Similarly, $E_{B 1}$ and $E_{B 2}$ are used to denote the expected payoff of the passengers taking the "No Default" strategy and "Default" strategies, and $\bar{E}_{B}$ is defined as the averaged payoff of the passengers.

$$
\begin{gathered}
E_{B 1}=x U+(1-x) U^{\prime}-R, \\
E_{B 2}=x U+(1-x) U^{\prime}-L_{B}, \\
\bar{E}_{B}=y E_{B 1}+(1-y) E_{B 2} .
\end{gathered}
$$

The replicated dynamic equation of $E_{B 1}$ is given by:

$$
F_{2}(y)=\frac{d y}{d t}=y\left(E_{B 1}-\bar{E}_{B}\right)=y(1-y)\left(L_{B}-R\right)
$$

According to Friedman [49] and Esmaeili et al. [50], ESS can be derived from local stability analysis of the Jacobian matrix of the replicator dynamic system. Equations (4) and (8) form the replicator dynamic system (I). Taking the derivatives of $x$ and $y$ of the replicator 
dynamic system (I) to determine the final ESS in the game, the Jacobian matrix can be obtained as follows:

$$
\begin{aligned}
J_{I} & =\left[\begin{array}{ll}
\frac{\partial F_{1}(x)}{\partial x} & \frac{\partial F_{1}(x)}{\partial y} \\
\frac{\partial F_{2}(y)}{\partial x} & \frac{\partial F_{2}(y)}{\partial y}
\end{array}\right] \\
& =\left[\begin{array}{cc}
(1-2 x)\left(L_{S}-M\right) & 0 \\
0 & (1-2 y)\left(L_{B}-R\right)
\end{array}\right]
\end{aligned}
$$

According to Selten [51], the ESS is a pure strategy for an asymmetric game if there exists information asymmetry. Specifically, the equilibrium point is ESS, when all eigenvalues of Jacobian matrix corresponding to it are negative [52]. Hence, we would only discuss the stability of the Nash equilibrium point of pure strategy, and Proposition 1 can be derived by discussing the stability of four equilibrium points $(0,0),(0,1),(1,0)$, and $(1,1)$.

\section{Proposition 1.}

(1) When $L_{S}>M$ and $L_{B}>R,(1,1)$ is the ESS of the replicator dynamic system (I) and the strategy is (S1,B1).

(2) When $L_{S}>M$ and $L_{B}<R,(1,0)$ is the ESS of the replicator dynamic system (I) and the strategy is $(S 1, B 2)$.

(3) When $L_{S}<M$ and $L_{B}>R,(0,1)$ is the ESS of the replicator dynamic system (I) and the strategy is $(S 2, B 1)$.

(4) When $L_{S}<M$ and $L_{B}<R,(0,0)$ is the ESS of the replicator dynamic system (I) and the strategy is $(S 2, B 2)$.

Proof 1. We substituted the four equilibrium points $(0,0),(0,1),(1,0)$, and $(1,1)$ into the Jacobian matrix, and the eigenvalues corresponding to each equilibrium point can be obtained, as shown in Table 4.

Table 4. The eigenvalues of the equilibrium points of scenario 1.

\begin{tabular}{ccc}
\hline The Equilibrium Point & Eigenvalues $\mathbf{1}$ & Eigenvalues 2 \\
\hline$(0,0)$ & $L_{S}-M$ & $L_{B}-R$ \\
$(0,1)$ & $L_{S}-M$ & $R-L_{B}$ \\
$(1,0)$ & $M-L_{S}$ & $L_{B}-R$ \\
$(1,1)$ & $M-L_{S}$ & $R-L_{B}$ \\
\hline
\end{tabular}

Based on the principles to judge the stability of the abovementioned equilibrium points, we can obtain the conclusion of Proposition 1 from the results of Table 4 .

From Proposition 1, we can know that if $L_{S}>M$ and $L_{B}>R$, the strategy combination (S1, B1) will be reached, which was our aim. In other words, if the credit constraint is strong enough, the default risk can be controlled by the credit constraint of users without supervision. Given that China's credit system is still in the accelerated construction stage [53], the credit system has limited constraints on drivers and passengers; thus, we need to further study the internal supervision of the platform enterprises.

\subsubsection{Scenario 2: Internal Supervision}

In scenario 2, we incorporated the strategy of the platform enterprises into the evolutionary game, that is, the platform enterprises can choose between the "Supervision" strategy and the "No Supervision" strategy. In the case of platform enterprises adopting "No Supervision" strategy, the payoff of game participants is the same as that in basic model, as shown in Table 3. In the case of platform enterprises adopting "Supervision" strategy, the payoff of each game participant is shown in Table 5. In this case, when the driver chooses the "Normal Service" strategy and the passenger chooses the "No Default" 
strategy, the decision choice of the three parties is (S1, B1, T1). Thus, the driver can still gain $R-K$, and the passenger can gain $U-R$, while the platform enterprise can gain the commission fee deducted from the supervision cost $K-C$. When the driver chooses the "Normal Service" strategy and the passenger chooses the "Default" strategy, the decision choice of the three parties is (S1, B2, T1). Thus, the driver cannot achieve their desired service price and their payoff is 0 . The passenger obtains a utility $U$ but suffers a loss $L_{B}$ and a punishment $W_{B}$, and the platform enterprise receives the fines from the passenger. When the driver chooses the "Abnormal Service" strategy and the passenger chooses the "No Default" strategy, the decision choice of the three parties is (S2, B1, T1). Thus, the driver achieves their desired service price and an additional revenue, and their payoff is $M+R-K-L_{S}-W_{S}$. The passenger obtains a utility $U^{\prime}$ and pay $R$, while the platform enterprise's payoff is $K-C+W_{S}$. When the driver chooses the "Abnormal Service" strategy and the passenger chooses the "Default" strategy, the decision choice of the three parties is (S2, B2, T1). Thus, the driver's payoff is $M-L_{S}-W_{S}$ and the passenger's payoff is $U^{\prime}-L_{B}-W_{B}$, while the platform enterprise's payoff is $-C+W_{S}+W_{B}$.

Table 5. Benefit matrix of online car-hailing platform of scenario 2 (when the platform enterprise chooses the "Supervision" strategy).

\begin{tabular}{ccc}
\hline & No Default & Default \\
\hline Normal Service & $R-K, U-R, K-C$ & $0, U-L_{B}-W_{B},-C+W_{B}$ \\
Abnormal Service & $M+R-K-L_{S}-W_{S}, U^{\prime}-$ & $M-L_{S}-W_{S}, U^{\prime}-L_{B}-$ \\
& $R, K-C+W_{S}$ & $W_{B},-C+W_{S}+W_{B}$ \\
\hline
\end{tabular}

Note: The first item is the payoff of the drivers, the second item is the payoff of the passengers, and the third item is the payoff of the platform enterprises.

Similarly, the replicated dynamic equation of the driver taking the "Normal Service" strategy is given by:

$$
G_{1}(x)=x(1-x)\left(L_{S}-M+z W_{S}\right)
$$

The replicated dynamic equation of the passenger taking the "No Default" strategy is given by:

$$
G_{2}(y)=y(1-y)\left(L_{B}-R+z W_{B}\right) .
$$

The replicated dynamic equation of platform enterprise taking the "Supervision" strategy is given by:

$$
G_{3}(z)=z(1-z)\left[-C+(1-x)\left(L_{S T}+W_{S}\right)+(1-y)\left(L_{B T}+W_{B}\right)\right] .
$$

Equations (10)-(12) form the replicator dynamic system (II). Taking the derivatives of $x$ and $y$ of the replicator dynamic system (II) to determine the final ESS in the game, the Jacobian matrix can be obtained as follows:

$$
\begin{gathered}
J_{I I}=\left[\begin{array}{ccc}
\frac{\partial G_{1}(x)}{\partial x} & \frac{\partial G_{1}(x)}{\partial y} & \frac{\partial G_{1}(x)}{\partial z} \\
\frac{\partial G_{2}(y)}{\partial x} & \frac{\partial G_{2}(y)}{\partial y} & \frac{\partial G_{2}(y)}{\partial z} \\
\frac{\partial G_{3}(z)}{\partial x} & \frac{\partial G_{3}(z)}{\partial y} & \frac{\partial G_{3}(z)}{\partial z}
\end{array}\right] \\
=\left[\begin{array}{ccc}
(1-2 x)\left(L_{S}-M+z W_{S}\right) & 0 & x(1-x) W_{S} \\
0 & (1-2 y)\left(L_{B}-R+z W_{B}\right) & y(1-y) W_{B} \\
-z(1-z) Q_{1} & -z(1-z) Q_{2} & (1-2 z)\left[-C+(1-x) Q_{1}+(1-y) Q_{2}\right]
\end{array}\right],
\end{gathered}
$$

where

$$
\begin{aligned}
& Q_{1}=L_{S T}+W_{S} \\
& Q_{2}=L_{B T}+W_{B} .
\end{aligned}
$$


Further, we called the equilibrium points $(1,1,0)$ and $(1,1,1)$ the preferred equilibrium points, as they mean that the default risk has been controlled. In addition, Proposition 2 can be derived by discussing the stability of preferred equilibrium points.

Proposition 2. The preferred equilibrium point $(1,1,0)$ is the ESS of the replicator dynamic system (II) when $L_{S}>M$ and $L_{B}>R$. Otherwise, the preferred equilibrium points cannot be the ESS of the replicator dynamic system (II).

Proof 2. Substituting the eight equilibrium points $(0,0,0),(0,0,1),(0,1,0),(1,0,0),(0,1,1)$, $(1,0,1),(1,1,0)$, and $(1,1,1)$ into the Jacobian matrix, the eigenvalues corresponding to each equilibrium point can be obtained, as shown in Table 6.

Table 6. The eigenvalues of the equilibrium points of scenario 2 .

\begin{tabular}{cccc}
\hline $\begin{array}{c}\text { The Equilibrium } \\
\text { Point }\end{array}$ & Eigenvalue 1 & Eigenvalue 2 & Eigenvalue 3 \\
\hline$(0,0,0)$ & $L_{S}-M$ & $L_{B}-R$ & $-C+Q_{1}+Q_{2}$ \\
$(0,0,1)$ & $L_{S}-M+W_{S}$ & $L_{B}-R+W_{B}$ & $C-Q_{1}-Q_{2}$ \\
$(0,1,0)$ & $L_{S}-M$ & $R-L_{B}$ & $-C+Q_{1}$ \\
$(1,0,0)$ & $M-L_{S}$ & $L_{B}-R$ & $-C+Q_{2}$ \\
$(0,1,1)$ & $L_{S}-M+W_{S}$ & $R-L_{B}-W_{B}$ & $C-Q_{1}$ \\
$(1,0,1)$ & $M-L_{S}-W_{S}$ & $L_{B}-R+W_{B}$ & $C-Q_{2}$ \\
$(1,1,0)$ & $M-L_{S}$ & $R-L_{B}$ & $-C$ \\
$(1,1,1)$ & $M-L_{S}-W_{S}$ & $R-L_{B}-W_{B}$ & $C$ \\
\hline
\end{tabular}

From the result of Table 6 , for preferred equilibrium points $(1,1,0)$, all eigenvalues of Jacobian matrix corresponding to it are negative only when $L_{S}>M$ and $L_{B}>R$. For preferred equilibrium points $(1,1,1)$, one of the eigenvalues is $C$, as can be seen from Table 6 . As $C>0,(1,1,1)$ would not be the ESS. Hence, based on the principles to judge the stability of the abovementioned equilibrium points, we can obtain the conclusion of Proposition 2 from the results of Table 6.

From Proposition 2, we can know that the default risk cannot be controlled under the internal supervision environment if the credit constraint in scenario 1 is not strong enough. In other words, due to the pursuit of the platform enterprise's own interests, the supervision function of said platform enterprise makes little contribution to the default risk control.

\subsubsection{Scenario 3: External Supervision}

In scenario 2, we incorporated the internal supervision into the evolutionary game, that is, the platform enterprises monitoring the behavior of the platform users and punishing them they when default. From Proposition 2, we know that the internal supervision mechanism cannot achieve the goal of controlling default risk when the credit constraint is not great enough. Therefore, we studied the external supervision, and we analyzed three different situations, namely direct supervision imposed by the regulators on the platform users, supervision of the platform enterprises' monitoring results (post-event supervision), and supervision of the platform enterprises' monitoring behaviors (in-event supervision).

\section{Analysis of Direct Supervision}

First of all, we considered the situation in which the regulators directly supervise the platform users, that is, the regulators punish the default behaviors of the platform users. Actually, this direct supervision of the regulators has no impact on the payoff of the platform enterprises, and the impact on the platform users can be represented by the adjustment of $L_{S}$ and $L_{B}$. Hence, according to Proposition 2, we can conclude that if the punishment for the platform users imposed by the regulators is strong enough, 
the default risk of said platform users can be controlled. However, in that case, the platform enterprises will always choose the "No Supervision" strategy. Given that the supervision cost of regulators is often higher than that of the platform enterprises, it is still necessary to further study the ways of indirect supervision.

Analysis of Indirect Supervision (Post-Event)

Next, we considered the situation that the regulators supervise the monitoring results of the platform enterprises, which is also called post-event supervision. In other words, in the case of default by the drivers or passengers, if the platform enterprises fail to punish them, the regulators will impose penalties on the platform enterprises. Given that this situation has no impact on the platform users, the replicated dynamic equation of the platform users is also given by Equations (10) and (11).

The replicated dynamic equation of the platform enterprises taking the "Supervision" strategy is given by:

$$
H_{1}(z)=z(1-z)\left[-C+(1-x) Q_{1}+(1-y) Q_{2}+(1-x y) W\right] .
$$

Equations (10), (11), and (16) form the replicator dynamic system (III), and we still substituted eight equilibrium points $(0,0,0),(0,0,1),(0,1,0),(1,0,0),(0,1,1),(1,0,1),(1,1,0)$, and $(1,1,1)$ into the Jacobian matrix and obtained the eigenvalues corresponding to these eight equilibrium points, which are shown in Table 7.

Table 7. The eigenvalues of the equilibrium points of scenario 3 (post-event supervision).

\begin{tabular}{cccc}
\hline $\begin{array}{c}\text { The Equilibrium } \\
\text { Point }\end{array}$ & Eigenvalue 1 & Eigenvalue 2 & Eigenvalue 3 \\
\hline$(0,0,0)$ & $L_{S}-M$ & $L_{B}-R$ & $-C+Q_{1}+Q_{2}+W$ \\
$(0,0,1)$ & $L_{S}-M+W_{S}$ & $L_{B}-R+W_{B}$ & $C-Q_{1}-Q_{2}-W$ \\
$(0,1,0)$ & $L_{S}-M$ & $R-L_{B}$ & $-C+Q_{1}+W$ \\
$(1,0,0)$ & $M-L_{S}$ & $L_{B}-R$ & $-C+Q_{2}+W$ \\
$(0,1,1)$ & $L_{S}-M+W_{S}$ & $R-L_{B}-W_{B}$ & $C-Q_{1}-W$ \\
$(1,0,1)$ & $M-L_{S}-W_{S}$ & $L_{B}-R+W_{B}$ & $C-Q_{2}-W$ \\
$(1,1,0)$ & $M-L_{S}$ & $R-L_{B}$ & $-C$ \\
$(1,1,1)$ & $M-L_{S}-W_{S}$ & $R-L_{B}-W_{B}$ & $C$ \\
\hline
\end{tabular}

It can easily be seen that the results of preferred equilibrium points in Table 7 are similar to those in Table 6, indicating that the default risk cannot be controlled under the situation of post-event supervision if the credit constraint in the basic model is not strong enough. In other words, this kind of external supervision makes no improvement to the default risk control.

Analysis of Indirect Supervision (In-Event)

Finally, we considered the situation in which the regulators supervise the behavior of the platform enterprises, which is also called in-event supervision. In other words, if the platform enterprises do not choose the "Supervision" strategy, the regulators will impose penalties on the platform enterprises. Similarly, this situation has no impact on the platform users, so the replicated dynamic equation of the platform users is still given by Equations (10) and (11).

The replicated dynamic equation of the platform enterprises taking the "Supervision" strategy is given by:

$$
H_{2}(z)=z(1-z)\left[W^{\prime}-C+(1-x) Q_{1}+(1-y) Q_{2}\right] .
$$

Equations (10), (11), and (17) form the replicator dynamic system (IV), and we still substituted eight equilibrium points $(0,0,0),(0,0,1),(0,1,0),(1,0,0),(0,1,1),(1,0,1),(1,1,0)$, 
and $(1,1,1)$ into the Jacobian matrix and obtained the eigenvalues corresponding to these eight equilibrium points, which are shown in Table 8.

Table 8. The eigenvalues of the equilibrium points of scenario 3 (in-event supervision).

\begin{tabular}{cccc}
\hline $\begin{array}{c}\text { The Equilibrium } \\
\text { Point }\end{array}$ & Eigenvalue 1 & Eigenvalue 2 & Eigenvalue 3 \\
\hline$(0,0,0)$ & $L_{S}-M$ & $L_{B}-R$ & $W^{\prime}-C+Q_{1}+Q_{2}$ \\
$(0,0,1)$ & $L_{S}-M+W_{S}$ & $L_{B}-R+W_{B}$ & $-W^{\prime}+C-Q_{1}-Q_{2}$ \\
$(0,1,0)$ & $L_{S}-M$ & $R-L_{B}$ & $W^{\prime}-C+Q_{1}$ \\
$(1,0,0)$ & $M-L_{S}$ & $L_{B}-R$ & $W^{\prime}-C+Q_{2}$ \\
$(0,1,1)$ & $L_{S}-M+W_{S}$ & $R-L_{B}-W_{B}$ & $-W^{\prime}+C-Q_{1}$ \\
$(1,0,1)$ & $M-L_{S}-W_{S}$ & $L_{B}-R+W_{B}$ & $-W^{\prime}+C-Q_{2}$ \\
$(1,1,0)$ & $M-L_{S}$ & $R-L_{B}$ & $W^{\prime}-C$ \\
$(1,1,1)$ & $M-L_{S}-W_{S}$ & $R-L_{B}-W_{B}$ & $C-W^{\prime}$ \\
\hline
\end{tabular}

Proposition 3. The preferred equilibrium point $(1,1,1)$ is the ESS of the replicator dynamic system (IV) when $W_{S}>M-L_{S}, W_{B}>R-L_{B}$, and $W^{\prime}>C$.

Proof 3. From the result of Table 8, all eigenvalues of Jacobian matrix corresponding to $(1,1,1)$ are negative when $W_{S}>M-L_{S}, W_{B}>R-L_{B}$, and $W^{\prime}>C$. Based on the principles to judge the stability of the equilibrium points, we can obtain the conclusion of Proposition 3.

Actually, Proposition 3 indicates that if the intensity of supervision of the regulators and the platform enterprises is great enough, the default risk of the platform users can be controlled even if the credit constraint is not strong. Given that the aims of direct and in-event supervision imposed by the regulators are making $M-L_{S}-W_{S}$ and $R-L_{B}-W_{B}$ less than 0 , it is more appropriate to apply the in-event supervision mode. In other words, it is more costly to increase $L_{S}$ and $L_{B}$ than $W_{S}$ and $W_{B}$ to achieve the same goal. Here, the cost of the regulators supervising the platform enterprises is not taken into consideration, as the cost of regulation can be decrease by setting up a random supervision mechanism. Actually, the cost of regulation is much lower when monitoring a single object.

\section{Discussion}

\subsection{Numerical Simulation}

In order to describe the evolution process of each scenario clearly, we used MATLAB $\mathrm{R} 2012 \mathrm{~b}$ software to simulate the evolution paths of the drivers, passengers, and platform enterprises.

\subsubsection{Numerical Simulation and Discussion of Scenario 1}

For scenario 1, the evolution paths are shown in Figure 4. From the results in Figure 4, for scenario 1, users are prompted to take the compliance actions when the credit constraint is strong. In the case of weak credit constraints, the lack of supervision results in the platform users taking the default actions, and social welfare is the lowest.

In Case 1, we set $L_{S}=4, L_{B}=4, M=2$, and $R=2$, which meet the condition of $L_{S}>M, L_{B}>R$. We chose several initial points to simulate the evolution process, and we set the starting time to 0 and the terminal time to 5 . The simulation results of the general evolution tendency are shown in Figure 4a. In this case, $(1,1)$ is the ESS of the evolutionary game, which indicates that if the credit constraint is strong enough, the default risk can be controlled by the credit constraint of the users without supervision.

In Case 2, we set $L_{S}=4, L_{B}=2, M=2$, and $R=4$, which meet the condition of $L_{S}>M, L_{B}<R$. Similarly, we chose several initial points to simulate the evolution process, and we set the starting time to 0 and the terminal time to 5 . The simulation results of the general evolution tendency are shown in Figure $4 \mathrm{~b}$. In this case, $(1,0)$ is the ESS of 
the evolutionary game, indicating that if there is no effective restraint on the passengers, the passengers will always take default actions, which was not our aim.

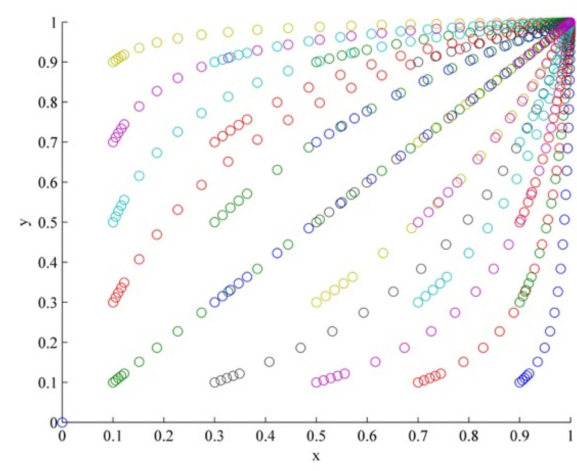

(a)

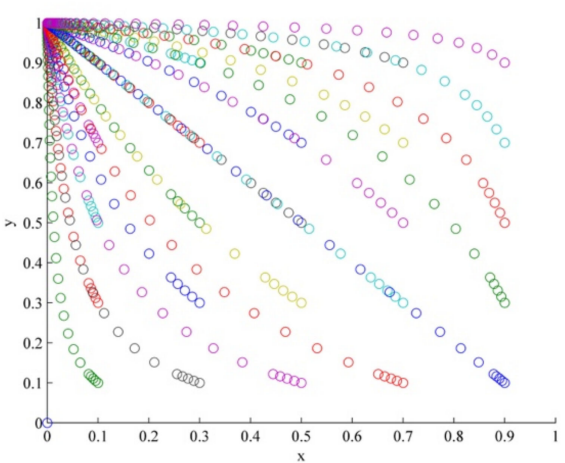

(c)

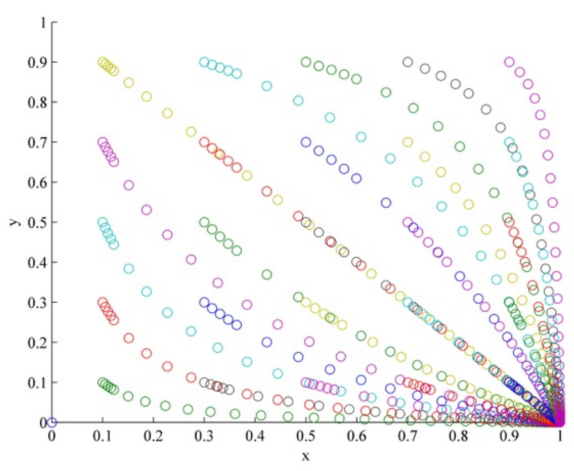

(b)

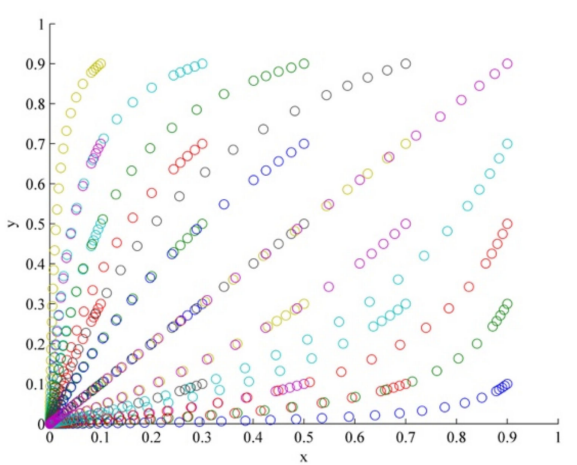

(d)

Figure 4. Evolution paths of Cases 1 to 4 in scenario 1. (a) Case 1: $L_{S}>M, L_{B}>R$; (b) Case 2: $L_{S}>M, L_{B}<R$; (c) Case 3: $L_{S}<M, L_{B}>R$; (d) Case 4: $L_{S}<M, L_{B}<R$. Circles in the same color indicate the evolutionary path of the same initial point.

In Case 3, we set $L_{S}=2, L_{B}=4, M=4$, and $R=2$, which meet the condition of $L_{S}<M, L_{B}>R$. We chose several initial points to simulate the evolution process, and we set the starting time to 0 and the terminal time to 5 . The simulation results of the general evolution tendency are shown in Figure $4 \mathrm{c}$. In this case, $(0,1)$ is the ESS of the evolutionary game, indicating that if there is no effective restraint on drivers, the drivers will always take default actions, which was not our aim.

In Case 4 , we set $L_{S}=2, L_{B}=2, M=4$, and $R=4$, which meet the condition of $L_{S}<M, L_{B}<R$. We chose several initial points to simulate the evolution process, and we set the starting time to 0 and the terminal time to 5 . The simulation results of the general evolution tendency are shown in Figure $4 \mathrm{~d}$. In this case, $(0,0)$ is the ESS of the evolutionary game, and social welfare is the lowest.

\subsubsection{Numerical Simulation and Discussion of Scenario 2}

As the credit mechanism has limited constraints on the drivers and passengers [53], we incorporated internal supervision into the evolutionary game, which refers to scenario 2. The supervision imposed by the platform enterprises is very important for coping with default risks [54,55]. We studied the case that the internal supervision is cost-effective, which means that the platform enterprises impose enough penalties on the platform users $\left(W_{S}>M-L_{S}, W_{B}>R-L_{B}\right)$ and the supervision benefits of the platform enterprises exceed the supervision cost $\left(Q_{1}+Q_{2}>C\right)$. In this case, we found that there was no ESS for the evolutionary game model. We set $L_{S}=4, L_{B}=1, M=6, R=2, L_{S T}=4, L_{B T}=1$, $W_{S}=3, W_{B}=2$, and $C=1$, which meet the conditions of $W_{S}>M-L_{S}, W_{B}>R-L_{B}$, and $Q_{1}+Q_{2}>C$. Similarly, we chose several initial points to simulate the evolution 
process. Here, we stretched out the time, setting the starting time to 0 and the terminal time to 50, in order to see the evolution tendency. The simulation results of the general evolution tendency are shown in Figure 5.

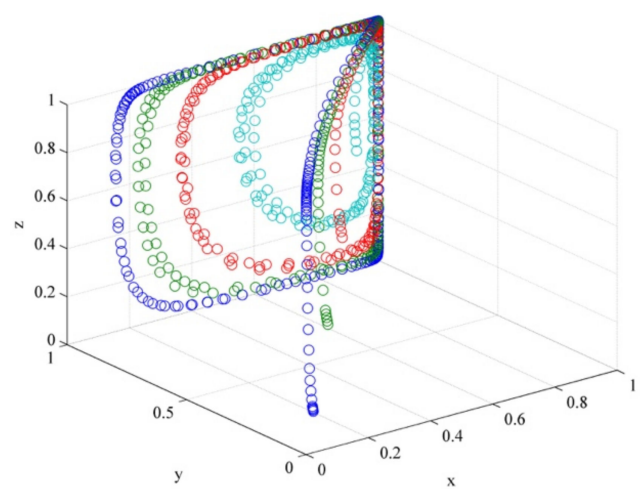

Figure 5. Evolution paths in scenario 2. Circles in the same color indicate the evolutionary path of the same initial point.

As can be seen from Figure 5, there exists a cycle path for the evolution process. When the platform enterprises penalize the platform users sufficiently, it encourages the platform users not to default, leading to the default risk being controlled in the short term. In the long term, due to the existence of supervision costs, there is no incentive for the platform enterprises to supervise when the default probabilities of the drivers and passengers are very low, and the "No Supervision" strategy would push the drivers and passengers back to the default stage. Hence, we needed to incorporate external supervision, which echoes Rauch and Schleicher's study that risk control in the sharing economy requires intervention from the regulators to make up the defects of internal supervision [56].

\subsubsection{Numerical Simulation and Discussion of Scenario 3}

As shown in our previous analysis, we had proved that in-event supervision can achieve the goal of controlling the default risk of the platform users if the intensity of the supervision of the regulators and the platform enterprises is great enough, even if the credit constraint is not strong. In this case, we set $L_{S}=4, L_{B}=1, M=6, R=2$, $L_{S T}=4, L_{B T}=1, W_{S}=3, W_{B}=2, C=1$, and $W^{\prime}=2$, which meet the condition of $W_{S}>M-L_{S}, W_{B}>R-L_{B}$, and $W^{\prime}>C$. Similarly, we chose several initial points to simulate the evolution process, and we set the starting time to 0 and the terminal time to 50. The simulation results of the general evolution tendency are shown in Figure 6.

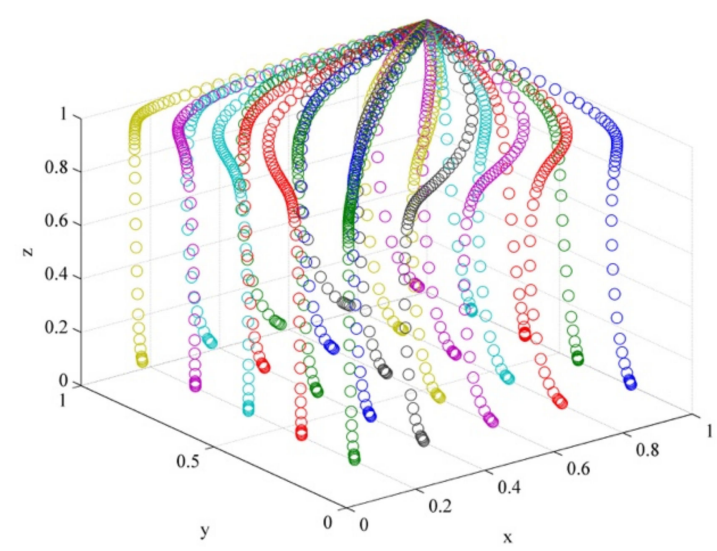

Figure 6. Evolution paths in scenario 3 (in-event supervision). Circles in the same color indicate the evolutionary path of the same initial point. 
It is worth noting that, compared to in-event supervision, a combination of in-event and post-event supervision accelerates the evolution of the platform users toward the compliance behavior strategy. To describe this finding clearly, we used MATLAB R2012b software to simulate the evolutionary equilibrium process of the strategy selection of the drivers and passengers. We set $L_{S}=4, L_{B}=1, M=6, R=2, L_{S T}=4, L_{B T}=1$, $W_{S}=3, W_{B}=2, C=1, W^{\prime}=2, W=10$, and the evolution paths are shown in Figure 7 .

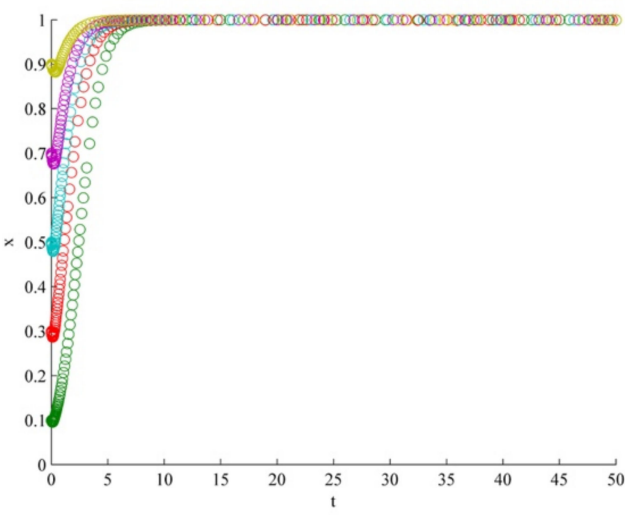

(a)

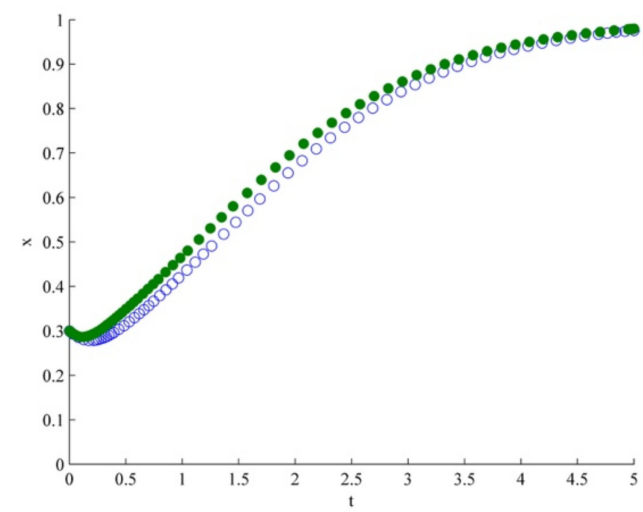

(c)

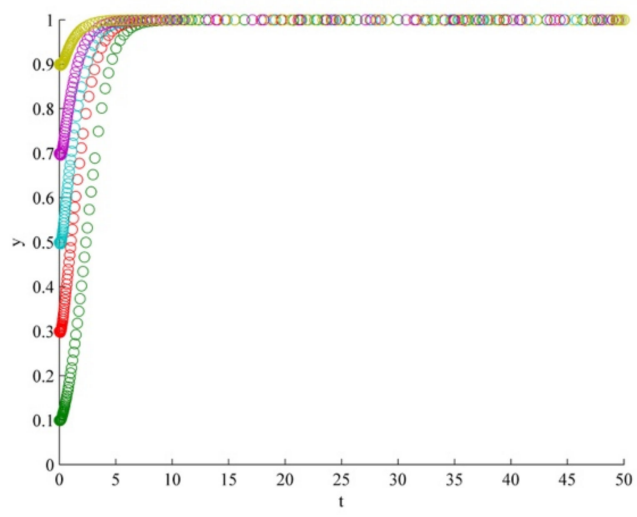

(b)

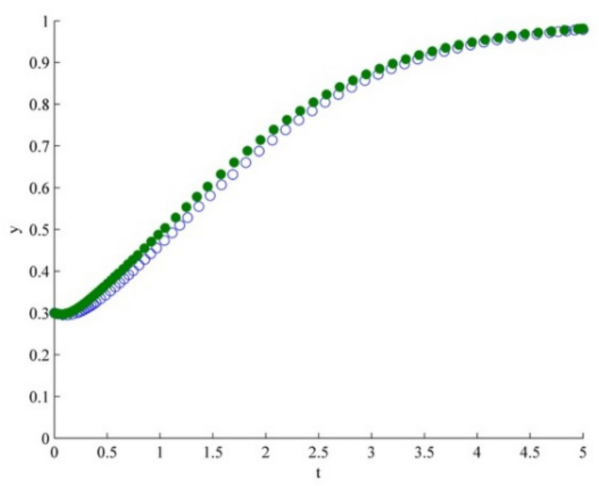

(d)

Figure 7. Evolution paths for the drivers and passengers under external supervision. (a) Evolution paths for the drivers under collaborative in-event and post-event supervision; (b) evolution paths for the passengers under collaborative in-event and post-event supervision; (c) comparison of evolution paths for the drivers under in-event supervision only (hollow circles) or collaborative in-event and post-event supervision (solid circles); (d) comparison of evolution paths for the passengers under in-event supervision only (hollow circles) or collaborative in-event and post-event supervision (solid circles). Circles in the same color indicate the evolutionary path of the same initial point.

As shown in Figure $7 \mathrm{c}, \mathrm{d}$, in the case of the same starting point, the adoption of collaborative in-event and post-event supervision can realize the non-default state of the drivers or the passengers more quickly. This conclusion provides a theoretical explanation of the Chinese government's practice that both in-event and post-event supervision should be conducted and strengthened [57].

\subsection{Mode and Strategies of Default Risk Supervision \\ 3.2.1. Supervision Mode}

Considering the high cost and difficulty of direct supervision by regulators [58], from Propositions 1-3, we propose a coordinated "platform enterprise + regulator "supervision mode (as shown in Figure 8) to control the default risk of platform users. Specifically, this coordinated supervision has triple meanings: First, regulators should formulate laws and regulations, while platform enterprises should establish platform rules; second, regulators 
should supervise platform enterprises, while platform enterprises should supervise platform users; third, regulators should supervise the supervisory behavior of platform enterprises.

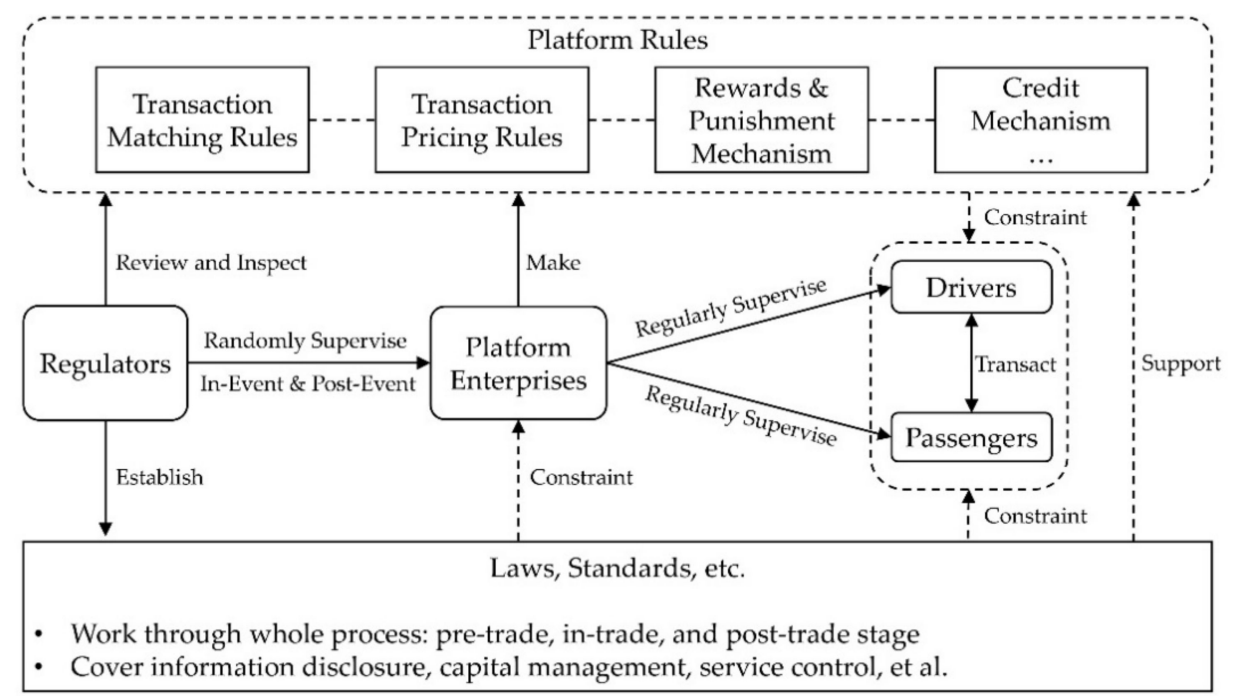

Figure 8. The coordinated supervision mode for the default risk of online car-hailing platforms.

In July 2016, the Ministry of Transport and other six ministries of China issued "The Interim Measures for the Management of Online Car-Hailing Operating Service", which stipulates the qualifications of platform enterprises and platform users (especially the drivers) and severely restricts their behaviors. Meanwhile, the regulations clarified the supervision responsibilities of platform enterprises over platform users [59]. In addition, a combination of direct supervision and indirect supervision imposed by regulators has been formed, which is consistent with our research. In May 2018, the General Office of the Ministry of Transport and other six relevant department of China issued one notification, called "Notice on strengthening the joint post-event and in-event supervision of the online car-hailing industry". This notification emphasizes the importance of multi-department joint supervision, and points out that both in-event and post-event supervision should be conducted and strengthened [57]. In addition to these regulatory practices, based on the supervision model proposed in our research, regulators should strengthen incentives for platform enterprises to make them more actively participate in supervision. Meanwhile, the supervision could focus more on aspects like qualification, historical reputation, service process, and capital management, and the platform rules should be regard as the critical point of supervision, to reduce direct supervision costs and improve supervision effectiveness.

\subsubsection{Supervision Strategies}

Based on the results of the evolutionary game model and the coordinated governance mode, we put forward several strategies for controlling default risk, namely promoting the construction of a credit system, strengthening the construction of laws and regulations, establishing a service process control mechanism, and introducing innovative regulatory means, as follows: (1) Promoting the construction of a credit system and perfecting the industry credit system. The establishment of a credit system is helpful for platform enterprises and platform users to obtain more credit information of their counterparties, and the punishment mechanism for default behavior can fully motivate platform enterprises and platform users. Regulators should introduce relevant laws and regulations on credit system construction in due course, and encourage platform enterprises to establish credit databases on drivers and passengers. Moreover, the regulators should encourage credit data sharing among different industries and enterprises. (2) Strengthening the construction of laws and regulations, and defining the roles of all parties involved in online car-hailing platform. As for the construction of laws and regulations in the online car-hailing industry, 
we need to attach equal importance to development and regulation, and establish certain rules and constraints for platform enterprises and users in accordance with the principle of encouraging innovation, inclusiveness, and prudence. Furthermore, the regulators should guide platform enterprises to actively explore the control mechanism for default risk, provide platform enterprises certain legal status support, to realize the effective supervision of platform users. (3) Establishing a service process control mechanism and disclosing the relevant information. The service process control mechanism should cover the whole service process to reduce the abnormal income of drivers and passengers. Further, the regulators should make efforts to supervise the said control mechanism to promote an effective operation. At the same time, platform enterprises should disclose relevant information such as platform rules, platform operations, and users' credit information in a timely manner, in order to alleviate information asymmetry. DiDi, for example, has already developed a stringent driver verification system and a monitoring system of driver behaviors. (4) Introduce innovative regulatory means to reduce regulatory costs. Regulators and platform enterprises should pay attention to the introduction of innovative regulatory means, including the application of Big Data and other technical means, to achieve a more accurate supervision. At the same time, the innovative regulatory means can do help to reduce the supervision costs and alleviate the problem of information distortion in the Internet trading environment.

\section{Conclusions}

This research applied the method of evolutionary game theory, constructed an evolutionary game model containing drivers, passengers, and platform enterprises, and investigated different scenarios of supervision. The main conclusions of this research are as follows: (1) If the credit constraint of the online car-hailing platform is strong, effective control of default risk can be achieved without the introduction of supervision by platform enterprises or regulators. (2) In the case of insufficient credit constraints in the online car-hailing platform, the internal supervision by platform enterprises will fail to effectively control default risk in the long run due to the existence of supervision costs, that is, there is no ESS of the evolutionary game model in which the default risk is controlled. (3) If the supervision intensity of regulators and platform enterprises is strong enough, even if the credit constraint is not strong, default risk can be controlled, that is, there is an ESS of the evolutionary game model in which the default risk can be controlled. In addition, a combination of post-event and in-event supervision can enhance the effect of external supervision.

On this basis, this research put forward the coordinated governance mode and several suggested strategies for controlling default risk, namely promoting the construction of a credit system, strengthening the construction of laws and regulations, establishing a service process control mechanism, and introducing innovative regulatory means. The coordinated governance mode and strategies were put forward based on the transaction relationship and market organization form of online car-hailing platform. In this way, this research does help to advance the understanding of the platform enterprises' operating process, and the conclusion would be able to extended to other platform economy and sharing economy fields to some extent.

There are several limitations to this study. In order to focus on the supervisory behavior of platform enterprises, this research did not consider neither the issue of competition between different platform enterprises nor the market variation, which worth conducting further study. In addition, this research only modeled the default risk problem of online car-hailing platform and stimulated the corresponding situation, but lacks an empirical examination, which can be taken as a future research direction.

Author Contributions: Conceptualization, P.L. and Z.W.; methodology, Z.W.; software, Z.W.; validation, Z.W. and P.L.; formal analysis, Z.W. and P.L.; writing-original draft preparation, Z.W.; writing-review and editing, P.L.; visualization, Z.W. and P.L.; supervision, P.L.; project administration, P.L. All authors have read and agreed to the published version of the manuscript. 
Funding: This research received no external funding.

Institutional Review Board Statement: Not applicable.

Informed Consent Statement: Not applicable.

Data Availability Statement: The data is contained within this paper.

Acknowledgments: The authors would like to thank the anonymous reviewers for their criticisms and suggestions.

Conflicts of Interest: The authors declare no conflict of interest.

\section{References}

1. Weng, Z. Research on the Platformization and Default Risk Governance of Sharing Economy. Ph.D. Thesis, Fudan University, Shanghai, China, 2019.

2. Czernich, N.; Falck, O.; Kretschmer, T.; Woessmann, L. Broadband infrastructure and economic growth. Econ. J. 2011, 121, 505-532. [CrossRef]

3. Han, B.; Zhu, P. Empirical Analysis on Effect of Broadband on Economic Growth in China. Stat. Res. 2014, 31, 49-54.

4. Guo, J.; Luo, P. Does the Internet make contribution to TFP of China? Manag. World 2016, 10, 34-49.

5. Gao, Y.; Chen, J. The risk reduction and sustainable development of shared transportation: The Chinese online car-hailing policy evaluation in the digitalization era. Sustainability 2019, 11, 2596. [CrossRef]

6. Nikitas, A.; Kougias, I.; Alyavina, E.; Njoya Tchouamou, E. How can autonomous and connected vehicles, electromobility, BRT, hyperloop, shared use mobility and mobility-as-a-service shape transport futures for the context of smart cities? Urban Sci. 2017, 1,36. [CrossRef]

7. Rochet, J.C.; Tirole, J. Two-sided markets: A progress report. RAND J. Econ. 2006, 37, 645-667. [CrossRef]

8. Armstrong, M. Competition in two-sided markets. RAND J. Econ. 2006, 37, 668-691. [CrossRef]

9. China Internet Network Information Center. The 46th China Statistical Report on Internet Development. Available online: http:/ / www.cac.gov.cn/rootimages/uploadimg/1602953361765389/1602953361765389.pdf (accessed on 20 November 2020).

10. Edelman, B.; Geradin, D. Efficiencies and regulatory shortcuts: How should we regulate companies like Airbnb and Uber. Stanf. Technol. Law Rev. 2016, 19, 293-328. [CrossRef]

11. Rogers, B. The Social Costs of Uber. Univ. Chicago Law Rev. Online 2015, 82, 85-102. [CrossRef]

12. Jin, S.T.; Kong, H.; Wu, R.; Sui, D.Z. Ridesourcing, the sharing economy, and the future of cities. Cities 2018, 76, 96-104. [CrossRef]

13. Kim, K.; Baek, C.; Lee J, D. Creative destruction of the sharing economy in action: The case of Uber. Transp. Res. Part A Policy Pract. 2018, 110, 118-127. [CrossRef]

14. Tang, Q. The regulation path of sharing economy liked "special car". China Legal Sci. 2015, 4, $286-302$.

15. Luo, P.; Gu, D. Research on the influence path of venture capital on P2P platform transaction: A mediating effect model. Mod. Manag. 2018, 38, 1-4.

16. Melnik, M.I.; Alm, J. Does a seller's ecommerce reputation matter? Evidence from eBay auctions. J. Ind. Econ. 2002, 50, 337-349. [CrossRef]

17. Katzev, R. Car sharing: A new approach to urban transportation problems. Anal. Soc. Issues Public Policy 2003, 3, 65-86. [CrossRef]

18. Shaheen, S.; Martin, E. Assessing Early Market Potential for Carsharing in China: A Case Study of Beijing; Institute of Transportation Studies, UC Davis: Davis, CA, USA, 2006.

19. Firnkorn, J.; Müller, M. Free-floating electric carsharing-fleets in smart cities: The dawning of a post-private car era in urban environments? Environ. Sci. Policy 2015, 45, 30-40. [CrossRef]

20. Vanoutrive, T.; Van De Vijver, E.; Van Malderen, L.; Jourquin, B.; Thomas, I.; Verhetsel, A.; Witlox, F. What determines carpooling to workplaces in Belgium: Location, organisation, or promotion? J. Transp. Geogr. 2012, 22, 77-86. [CrossRef]

21. Yang, X.; Tu, K. Co-creation mechanism of users' value in sharing transportation: A case study of Uber. Manag. World 2017, 8, 154-169.

22. Chapman, D.A.; Eyckmans, J.; Van Acker, K. Does Car-Sharing Reduce Car-Use? An Impact Evaluation of Car-Sharing in Flanders, Belgium. Sustainability 2020, 12, 8155. [CrossRef]

23. Jung, J.; Koo, Y. Analyzing the effects of car sharing services on the reduction of greenhouse gas (GHG) emissions. Sustainability 2018, 10, 539. [CrossRef]

24. Rayle, L.; Dai, D.; Chan, N.; Cervero, R.; Shaheen, S. Just a better taxi? A survey-based comparison of taxis, transit, and ridesourcing services in San Francisco. Transp. Policy 2016, 45, 168-178. [CrossRef]

25. Anderson, D.N. “Not just a taxi"? For-profit ridesharing, driver strategies, and VMT. Transportation 2014, 41, 1099-1117. [CrossRef]

26. Glöss, M.; McGregor, M.; Brown, B. Designing for labour: Uber and the on-demand mobile workforce. In Proceedings of the 2016 CHI Conference on Human Factors in Computing Systems, San Jose, CA, USA, 7-12 May 2016; pp. 1632-1643.

27. Li, L. Default and legal regulation in online car-hailing market. Leg. Vis. 2016, 27, 18-19.

28. Zhou, B. Review of research on lemon market governance mechanism. Econ. Perspect. 2010, 3, 131-135.

29. Wu, J. Sharing economy, risk management and credit mechanism construction. Credit Ref. 2018, 36, 16-19. 
30. Lizzeri, A. Information revelation and certification intermediaries. RAND J. Econ. 1999, 30, 214-231. [CrossRef]

31. Albano, G.L.; Lizzeri, A. Strategic certification and provision of quality. Int. Econ. Rev. 2001, 42, 267-283. [CrossRef]

32. Stiglitz, J.E.; Weiss, A. Credit rationing in markets with imperfect information. Am. Econ. Rev. 1981, 71, $393-410$.

33. Bester, $\mathrm{H}$. The role of collateral in credit markets with imperfect information. Eur. Econ. Rev. 1987, 31, 887-899. [CrossRef]

34. Shi, L.; Zhao, R.; Le, J. Quantitative Management of Credit Risk in Commercial Banks. Shanghai J. Econ. 2003,4 , 44-51.

35. Gu, D.; Ding, L.; Luo, P. Evolutionary Game Analysis on Credit Risk Control in P2P Online Lending Platforms. RED Manag. 2018, 30, 12-21.

36. Wang, Y.; Liu, H.; Feng, Y. Public Regulation, Private Regulation and Coordinated Regulation in Platform Markets: A Comparative Study. Econ. Res. J. 2020, 55, 148-162.

37. Jin, J.; Zhuang, J.; Zhao, Q. Supervision after Certification: An Evolutionary Game Analysis for Chinese Environmental Labeled Enterprises. Sustainability 2018, 10, 1494. [CrossRef]

38. Zhao, J.; Wang, H.; Huang, Y.; Meng, Y. Does Massive Placement of Bicycles Win the Market for the Bicycle-Sharing Company in China? Sustainability 2020, 12, 5279. [CrossRef]

39. Jing, J.; Deng, X.; Maqbool, R.; Rashid, Y.; Ashfaq, S. Default Behaviors of Contractors under Surety Bond in Construction Industry Based on Evolutionary Game Model. Sustainability 2020, 12, 9162. [CrossRef]

40. Smith, J.M.; Price, G.R. The logic of animal conflict. Nature 1973, 246, 15-18. [CrossRef]

41. Taylor, P.D.; Jonker L, B. Evolutionary stable strategies and game dynamics. Math. Biosci. 1978, 40, 145-156. [CrossRef]

42. Smith, J.M. Evolution and the Theory of Games; Cambridge University Press: Cambridge, UK, 1982; pp. 40-67.

43. Weibull, J.W. Evolutionary Game Theory; MIT Press: Cambridge, UK, 1995; pp. 35-109.

44. Wang, X.; Quan, J.; Liu, W. Study on evolutionary games and cooperation mechanism within the framework of bounded rationality. Syst. Eng. Theory Pract. 2011, 31, 82-93.

45. Babu, S.; Mohan, U. An integrated approach to evaluating sustainability in supply chains using evolutionary game theory. Comput. Oper. Res. 2018, 89, 269-283. [CrossRef]

46. Park, O.; Shin, H.S.; Thourdos, A. Evolutionary Game Theory based Multi-Objective Optimization for Control Allocation of Over-Actuated System. IFAC Pap. OnLine 2019, 52, 310-315. [CrossRef]

47. Křivan, V.; Galanthay, T.E.; Cressman, R. Beyond replicator dynamics: From frequency to density dependent models of evolutionary games. J. Theor. Boil. 2018, 455, 232-248. [CrossRef] [PubMed]

48. Yang, W.; Yang, Y. Research on air pollution control in China: From the perspective of quadrilateral evolutionary games. Sustainability 2020, 12, 1756. [CrossRef]

49. Friedman, D. Evolutionary games in economics. Econometrica 1991, 59, 637-666. [CrossRef]

50. Esmaeili, M.; Allameh, G.; Tajvidi, T. Using game theory for analysing pricing models in closed-loop supply chain from short-and long-term perspectives. Int. J. Prod. Res. 2016, 54, 2152-2169. [CrossRef]

51. Selten, R. A note on evolutionarily stable strategies in asymmetric animal conflicts. J. Theor. Biol. 1980, 84, 93-101. [CrossRef]

52. Li, D.; Li, C.; Wang, S. Evolutionary Game of P2P Lending Platform Illegal Governance under Industry Self-Regulatory. Chin. J. Manag. Sci. 2020, 1-12. [CrossRef]

53. Liu, Y.; Chen, L.; Jin, S. Research on the application value of credit report in social governance. South China Financ. 2020, 8, 81-91.

54. Cohen, M.; Sundararajan, A. Self-Regulation and Innovation in the Peer-to-Peer Sharing Economy. Univ. Chicago Law Rev. Online 2015, 82, 116-133.

55. Kathan, W.; Matzler, K.; Veider, V. The sharing economy: Your business model's friend or foe? Bus. Horiz. 2016, 59, 663-672. [CrossRef]

56. Rauch, D.; Schleicher, D. Like Uber, But for Local Governmental Policy: The Future of Local Regulation of the 'Sharing Economy'. George Mason Law Econ. Res. Pap. 2015, 76, 1-60. [CrossRef]

57. Ministry of Transport of the People's Republic of China. Notice on Strengthening the Joint Post-Event and in-Event Supervision of the Online Car-Hailing Industry. Available online: http:/ /xxgk.mot.gov.cn/2020/jigou/ysfws/202006/t20200623_3315498.html (accessed on 20 November 2020).

58. Wang, X.; Zhang, Q. Research on Dual Management Paradigm of "Platform-Governance" in Platform-Mediated Network Market-A Case Study of Alibaba. China Ind. Econ. 2015, 3, 135-147.

59. Ministry of Transport of the People's Republic of China. The Interim Measures for the Management of Online Car-Hailing Operating Service. Available online: http://xxgk.mot.gov.cn/2020/jigou/fgs/202006/t20200623_3307798.html (accessed on 20 November 2020). 